\title{
Histologia do intestino do avestruz (Struthio camelus, Linnaeus 1758)
}

\author{
Histology of ostrich intestine (Struthio camelus, Linnaeus 1758)
}

\author{
Gisele SAVIANI ${ }^{1}$; Roselaine PONSO$^{2}$; Bruno COGLIATI ${ }^{3}$; Cintia Maria Monteiro de ARAÚJO ${ }^{4}$; \\ José Manoel dos SANTOS ${ }^{5}$; Arani Nanci Bonfim MARIANO ${ }^{6}$; Ricardo de ALBUQUERQUE ${ }^{7}$ \\ ${ }^{1}$ Médica Veterinária, Doutora em Anatomia dos Animais Domésticos e Silvestres da Faculdade de Medicina Veterinária \\ e Zootecnia da Universidade de São Paulo, São Paulo - SP, Brasil \\ ${ }^{2}$ Médica Veterinária, Doutora em Zootecnia, Faculdade de Medicina Veterinária e Zootecnia \\ da Universidade de São Paulo, São Paulo - SP, Brasil \\ ${ }^{3}$ Médico Veterinário, Doutor em Patologia, Faculdade de Medicina Veterinária e Zootecnia \\ da Universidade de São Paulo, São Paulo - SP, Brasil \\ ${ }^{4}$ Graduanda em Medicina Veterinária, Faculdade de Medicina Veterinária e Zootecnia \\ da Universidade de São Paulo, São Paulo - SP, Brasil \\ ${ }^{5}$ Coordenador do Curso de Bacharelado em Ciências Biológicas da Universidade Anhembi Morumbi, São Paulo - SP, Brasil \\ ${ }^{6}$ Professora Titular Aposentada em Anatomia dos Animais Domésticos e Silvestres da \\ Faculdade de Medicina Veterinária e Zootecnia da Universidade de São Paulo, São Paulo - SP, Brasil \\ ${ }^{7}$ Professor Titular do Departamento de Nutrição e Produção Animal da Faculdade de Medicina Veterinária \\ e Zootecnia da Universidade de São Paulo, São Paulo - SP, Brasil
}

\begin{abstract}
Resumo
A despeito de o avestruz (Struthio camelus) compartilhar muitas adaptações evolucionárias presentes em outras aves, estes animais apresentam algumas características anatômicas peculiares, como é o caso do seu tubo digestivo em que o cólon é maior que o ceco. Há algum tempo, essa ave tem sido explorada econômicamente e principalmente como fonte alternativa de proteína animal na alimentação humana. O presente trabalho analisou os aspectos histológicos do intestino de avestruzes produzidos em boas condições de manejo ambiental e nutricional. Foram utilizados 13 avestruzes, com 18 a 30 meses de idade, provenientes da empresa Brasil Ostrich, e encaminhados para o abate no Abatedouro Escola da Universidade de São Paulo, Campus Administrativo de Pirassununga. Os animais foram abatidos com pistola pneumática e, após a sangria e evisceração, foram colhidas amostras de diferentes segmentos do intestino: duodeno, jejuno, íleo e ceco duplo. Os materiais foram processados, corados pela técnica de hematoxilina-eosina (H-E) e examinados em microscopia de campo claro. Os resultados obtidos revelaram que as vilosidades estão presentes no duodeno, porém, não existem no ceco. Dos quatro segmentos intestinais examinados, o ceco foi o que apresentou maior número de células caliciformes. Os nódulos linfáticos e os linfócitos foram observados em todos os segmentos examinados. No ceco, os nódulos linfáticos se agregam para constituir a placa de Peyer. O plano histológico dos segmentos intestinais examinados seguiu o padrão observado nos mamíferos domésticos e em outras aves. O conhecimento da histologia dos intestinos desses animais pode oferecer subsídios para a avaliação comparativa de procedimentos de manejo ambiental e nutricional que possam aumentar os níveis de produção e produtividade dessa atividade pecuária.
\end{abstract}

Palavras-chave: Avestruz. Histologia animal. Intestinos. Nódulo linfoide.

\begin{abstract}
Regardless of the ostrich (Struthio camelus) share many adaptations to other evolutionary present birds, these animals show some peculiar anatomical features such as their digestive tract with the colon is greater than the cecum. For some time this bird has been economically exploited and especially as an alternative source of animal protein for human consumption. This study examined the histological bowel ostrich produced in good environmental management and nutrition. Thirteen ostriches were used, with 18 to 30 months old, from Brazil Ostrich company, and sent for slaughter in Slaughterhouse School, University of São Paulo Campus Administrative Pirassununga. The animals were killed with pneumatic gun and after bleeding and evisceration were collected, samples of different intestinal segments: duodenum, jejunum, ileum and cecum double. The materials were processed, stained with hematoxylin - eosin (HE) and examined under brightfield microscopy. The results showed that the villi are present in the duodenum but not exist in the cecum. Of the four intestinal segments examined the cecum showed the highest number of goblet cells. Lymph nodes and lymphocytes were observed in all segments examined. In the cecum lymph nodes are added to form the Peyer's patch. The plan of histological intestinal segments examined followed the pattern observed in other domestic mammals and birds. The knowledge of the histology of the intestines of these animals can provide insight for comparative assessment procedures for environmental management and nutrition that may increase the levels of production and productivity of this livestock activity.
\end{abstract}

Keywords: Ostrich. Histology animal. Intestines. Nodular lymphoid. 


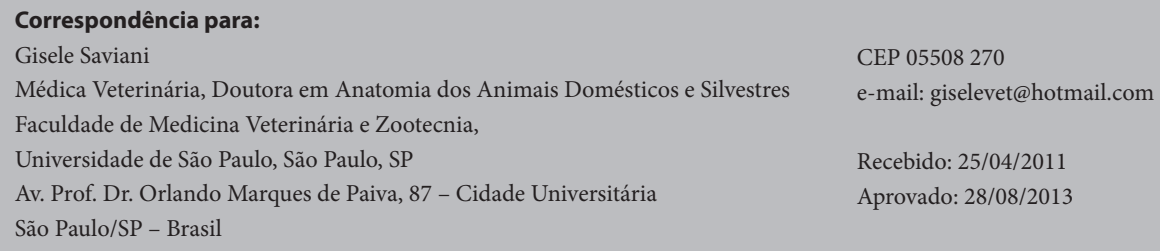

CEP 05508270

e-mail: giselevet@hotmail.com

Recebido: 25/04/2011

Aprovado: 28/08/2013

\section{Introdução}

A exploração econômica do avestruz, maior ave silvestre do mundo, domesticada em 1870, tem sido estimulada, pois as plumas e o couro destes animais apresentam elevado valor comercial e a sua carne se destaca devido ao baixo teor de colesterol (CARRER; KORNEFELD, 1999).

As patologias que afetam o trato digestório do avestruz, em princípio, são as mesmas que acometem as aves domésticas, no entanto, podem ocorrer variações na sua incidência relacionadas à susceptibilidade e resistência do animal. A maior incidência de transtornos digestivos no avestruz ocorre nos filhotes, principalmente até a quarta semana de idade. Os animais afetados mostram-se deprimidos e têm o seu desenvolvimento prejudicado. Quando apenas o intestino delgado é atingido, a diarreia pode não ser visível e o quadro pode se agravar, pois os avestruzes não possuem linfonodos mesentéricos, o que favorece a disseminação das infecções, que podem evoluir para um desfecho fatal (BEZUINDENHOUT, 1986). Os nódulos linfáticos da mucosa intestinal do avestruz são encontrados principalmente na base das vilosidades intestinais (DEEMING, 1999), onde o tecido linfoide aparece difuso ou forma agregados, principalmente no íleo, para constituir as estruturas denominadas placas de Peyer. A distribuição, arranjo e quantidade de tecido linfoide presente no intestino do animal desempenha importante papel da resposta imunológica local (ABBAS et al., 2000). Dessa maneira, o presente trabalho foi delineado para avaliar os aspectos histológicos dos diversos segmentos dos intestinos dos avestruzes, explorados economicamente em boas condições de manejo ambiental e nutricional.

\section{Material e Métodos}

Foram utilizados 13 avestruzes, com 18 a 30 meses de idade, de ambos os sexos, provenientes da empresa Brasil-Ostrich, localizada na cidade de PirassunungaSP. O abate foi realizado no Abatedouro Escola da Universidade de São Paulo (FMVZ), campus de Pirassununga - São Paulo.

Os animais foram abatidos com pistola pneumática e, após a sangria e evisceração, os seus tratos intestinais foram isolados e trabalhados. As peças foram cortadas, lavadas em água corrente e pré-fixadas em solução de formalina a $10 \%$ por seis horas. A seguir, foram separadas amostras por segmento intestinal: duodeno (D), jejuno (J), íleo (I) e ceco (C) as quais foram recortadas, em fragmentos menores, individualmente, com aproximadamente $1 \mathrm{~cm}$ de comprimento. Em seguida, foram conservadas em álcool $70 \%$ até o momento do processamento realizado em, no máximo, dez dias após a colheita. Os demais procedimentos histológicos empregados foram representados por: inclusão em parafina e cortes de $5 \mathrm{~mm}$ de espessura em micrótomo tipo Leica RM 2035 seguido de coloração pela técnica de Hematoxilina e Eosina (H.E.) (GARTNER; HIATT, 1999).

\section{Resultados}

Histologicamente, a parede do intestino do avestruz apresenta uma túnica mucosa apoiada em uma submucosa que se assenta em uma túnica muscular. $\mathrm{O}$ revestimento externo da túnica muscular é constituído por uma túnica serosa. A túnica mucosa está separada da submucosa por uma camada de tecido muscular liso, a muscular da mucosa.

No duodeno (Figura 2-A), pode-se observar que a túnica mucosa $(\mathrm{M})$ é revestida por um epitélio colunar 


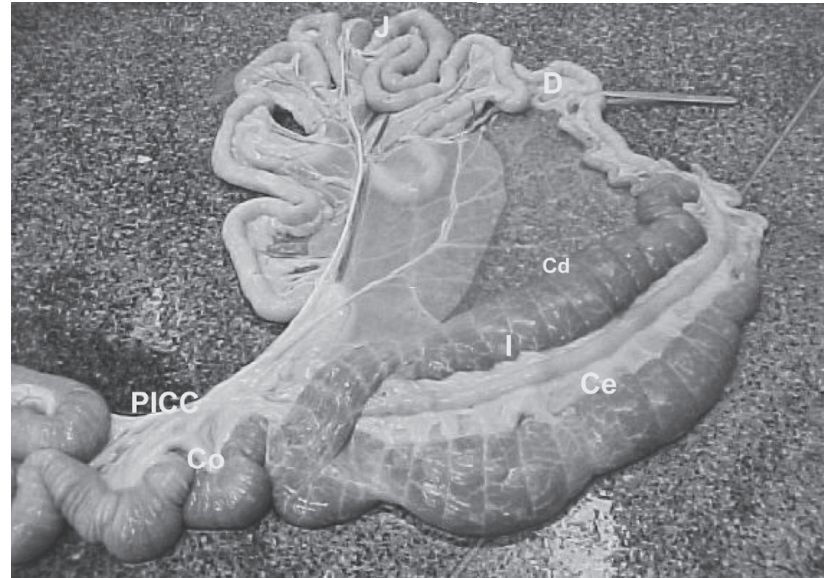

Figura 1 - Fotografia dos segmentos do aparelho digestório de avestruz (Struthio camelus)

Legenda: Relações anatômicas dos segmentos da região ileocecólica de um avestruz adulto. D - Duodeno, J - Jejuno, I - Íleo, Cd - Ceco direito, Ce - Ceco esquerdo, Co - Cólon e PICC - Prega íleo-ceco-cólica

Notas: foram coletadas amostras de 13 animais (entre 18 e 30 meses de idade), provenientes da empresa Brasil- Ostrich, situada na cidade de Pirassununga-São Paulo, abatidos no abatedouro Escola da Universidade de São Paulo (FMVZ), Campus de Pirassununga entre 2003 e 2004.

simples que apresenta células caliciformes e glândulas intestinais. Verifica-se, ainda, a presença da muscular da mucosa $(\mathrm{Mm})$ e, abaixo desta, a túnica submucosa $(\mathrm{Sm})$. Externamente à túnica submucosa, se encontra a túnica muscular $(\mathrm{Mu})$.

No jejuno (Figura 2-B), foram observadas células caliciformes $(\mathrm{Cc})$ entre as células epiteliais de revestimento presentes nas vilosidades e nas glândulas intestinais (GI). Na túnica mucosa $(\mathrm{M})$, foi registrada a presença de fibras musculares lisas formando a muscular da mucosa $(\mathrm{Mm})$, que separa a túnica mucosa (M) da túnica submucosa ( $\mathrm{Sm})$.

No ílio (Figura 2-C), foi constatado um maior número de células caliciformes do que o registrado nos demais segmentos examinados, as glândulas intestinais ( $\mathrm{gl}$ ) também foram observadas e a túnica mucosa (M) se apresentou com muscular da mucosa (Mm). Destaque-se, ainda, a presença de um aglomerado celular próximo ao nódulo linfoide $\left(^{*}\right)$ na mucosa $(\mathrm{M})$ e submucosa $(\mathrm{Sm})$ e a presença de um nódulo linfoide (NL) na submucosa. Na figura 2 (E) ainda no íleo, observa-se que o epitélio da glândula intestinal (Ep) apresenta células caliciformes (Cc) e linfócitos (L) entre as células de revestimento. Na lâmina própria foram registrados linfócitos (L0), linfoblastos (Lb) e plasmócitos (P).

No ceco (Figura 2-D), não foram constatadas vilosidades intestinais e as células caliciformes foram registradas em maior quantidade do que nos demais segmentos examinados. Também foi verificada a presença de túnica mucosa $(\mathrm{M})$, muscular da mucosa $(\mathrm{Mm})$ e, abaixo desta, a túnica submucosa $(\mathrm{Sm})$ contendo um aglomerado de nódulos linfoides que constituíram a placa de Peyer (Pp).

\section{Discussão}

Os diferentes segmentos do tubo digestório do avestruz jovem apresentam a mesma estrutura que o encontrado em outras aves, bem como nos mamíferos domésticos, porém, o seu intestino grosso é maior que o intestino delgado, característica já referida por Monteiro et al. (2009) e que foi confirmada no presente trabalho.

Como o avestruz é herbívoro, ele apresenta um trato digestivo distinto de outras aves e conta com algumas semelhanças com o de ruminantes domésticos, como bovinos, ovinos e caprinos (HUCHZERMEYER, 2000). Os achados do presente trabalho estão de acordo com o descrito por Aitken (1958); Mclelland (1986); Banks (1992); Bezuindehout e Aswegen (1990) e Junqueira e Carneiro (2004), que também verificaram que, ao longo do intestino, a túnica mucosa sofre modificações, apresentando uma diminuição do número de vilosidades no sentido do duodeno para o ceco.

A constatação no presente trabalho é que tanto no jejuno quanto no íleo, as vilosidades, as células caliciformes e o revestimento são efetuados por epitélio colunar simples, também verificada por Hodges (1974); Banks (1992); Young e Heath (2001) e Junqueira e Carneiro (2004). 

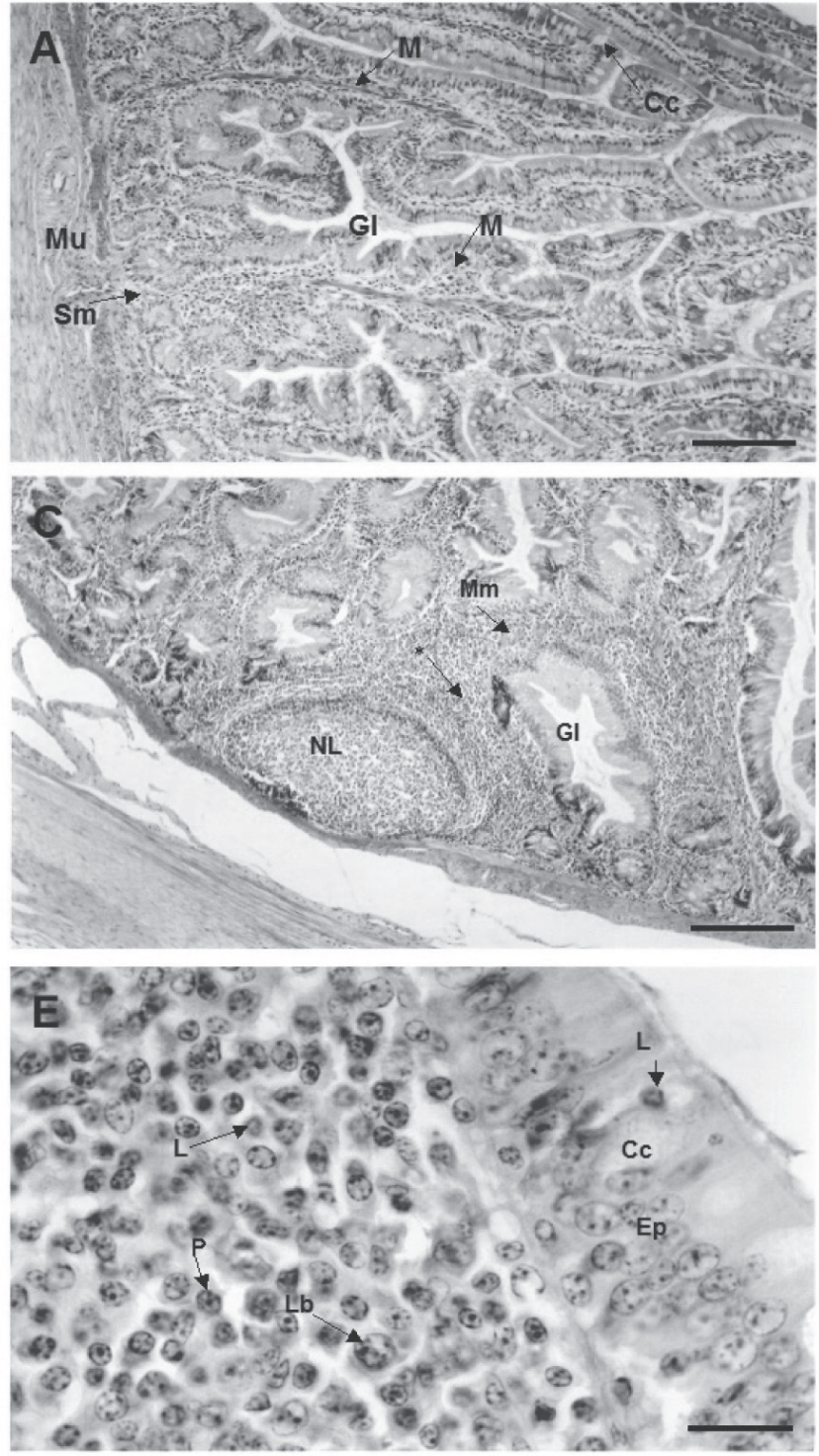

Figura 2 - (A), (B), (C), (D) e (E)

A observação de que a porção média do íleo de avestruzes apresenta vilosidades menores com grande quantidade de células caliciformes também foi registrada por Monteiro et al. (2009).

A verificação, no presente trabalho, de que os nódulos linfáticos ocasionalmente se agrupam ocupando parte da mucosa e parte da submucosa, formando um agregado de nódulos, que constitui a placa de Peyer, concorda com os registros de Young e Heath (2001), que observaram que as placas de Peyer são menos numerosas no duodeno e mais proeminentes no íleo terminal.
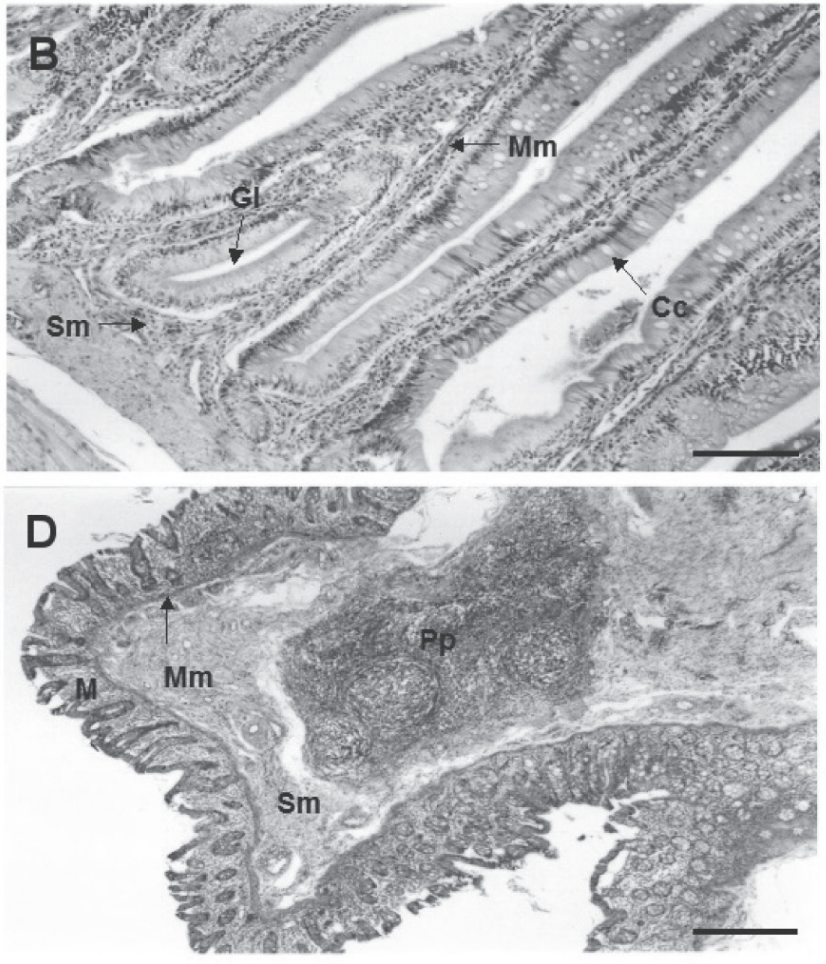

A - Fotomicrografia mostrando corte transversal do duodeno. Observar as células caliciformes (Cc), glândula intestinal (Gl), mucosa (M), muscular da mucosa (Mm) e submucosa (Sm). Notar a muscular (Mu) Técnica Hematoxilina e Eosina. Aumento $200 \mu \mathrm{m} . \exists$ - Fotomicrografia mostrando corte transversal do jejuno. Observar as células caliciformes (Cc), glândulas intestinais (Gl), muscular da mucosa (Mm) e submucosa (Sm). Técnica Hematoxilina e Eosina. Aumento $100 \mu \mathrm{m}$. C Fotomicrografia mostrando corte transversal do íleo. Observar as glândulas intestinais (GI) e na mucosa a presença da muscular da mucosa (Mm). Notar a presença de aglomerado celular próximo ao nódulo linfóide (") na mucosa e submucosa e a presença de um Nódulo linfóide $(\mathrm{NL})$ presente na submucosa Técnica Hematoxilina e Eosina. Aumento $200 \mu \mathrm{m}$. D - Fotomicrografia mostrando corte trarsversal do ceco. Observar a mucosa (M), muscular da mucosa (Mm), submucosa $(\mathrm{Sm})$ e Placa de Peyer $(\mathrm{Pp})$. Técnica Hematoxilina e Eosina. Aumento $200 \mathrm{um}$. E - Fotomicrografia mostrando parte da mucosa do lleo. Observar epitélio da glândula intestinal ( $\mathrm{Ep}$ ) constituido por células cilindricas e apresentando células caliciformes $(C c)$ e linfócitos $(L)$ entre as células de revestimento. Na lâmina própria observar linfócitos $(L)$, linfoblastos $(L b)$ e plasmócitos $(P)$. Técnica Hematoxilina e Eosina. Aumento $100 \mu \mathrm{m}$.

A ausência de vilosidades no ceco dos avestruzes examinados no presente trabalho também foi registrada por Junqueira e Carneiro (2004); Bezuindenhout (1990); Illanes (2006) e Monteiro et al. (2009). De fato, Maclelland (1986) referiu que no intestino grosso de algumas aves se observa a presença de vilosidades que diminuem em quantidade até desaparecerem no final do órgão (DELMANN, 1993; BACHA; BACHA, 2003; SAMUELSON, 2007).

A presença de células caliciformes, observada no presente trabalho, também foi verificada por George, Alves e Castro (1998) nos cecos das galinhas. 


\section{Conclusões}

A descrição histológica dos segmentos dos intestinos de avestruzes revelou a presença de vilosidades grandes no duodeno e ausência das mesmas no ceco. Observou-se que a quantidade de células caliciformes registradas no ceco foi muito superior à observada no duodeno. Os linfócitos foram verificados em todos os

\section{Referências}

ABBAS, S.; ABUL, K.; LICHTMAN, A. H.; POBER, J. S. Imunologia celular e molecular. Rio de Janeiro: Revinter, 2000. p. 32-33.

AITKEN, R. N. C. A histochemical study of the stomach and intestine of the chicken. Journal of Anatomy, v. 92, pt. 3, p. 453466,1958

BACHA, W. J.; BACHA, L. M. Atlas colorido de histologia veterinária. 2. ed. São Paulo: ROCA, 2003. 457 p.

BANKS, W. J. Histologia veterinária aplicada. 2. ed. São Paulo: Manole, 1992. p. 370-480.

BEZUINDENHOUT, A. J. The topograph of the thoracoabdominal viscera in the ostrich (Struthio camelus, Linnaeus 1758). The Onderstepoort Journal of Veterinary Research, v. 53, n. 2, p. 111-117, 1986.

BEZUINDENHOUT, A. J.; ASWEGEN, G. V. A light microscopic and immunocytochemical study of the gastrointestinal tract of the ostrich. The Onderstepoort Journal of Veterinary Research, v. 57, n. 1, p. $37-48,1990$.

CARRER, C.; KORNFELD, M. E. A criação de avestruzes. Pirassununga: C. C. Carrer, 1999. 303 p.

DEEMING, D. C. Biology, production and health. London: CABI Publishing, 1999. $358 \mathrm{p}$.

DELMANN, H. D. Textbook of veterinary histology. 4. ed. Philadelphia: Lea \& Febiger, 1993. 189 p. segmentos do intestino e os agregados dos nódulos linfoides foram encontrados apenas no ceco. O plano histológico dos segmentos de avestruz seguiu o mesmo padrão observado em mamíferos e aves.

Parte da Dissertação de mestrado da primeira autora, financiada pela FAPESP Proc.: 03/05632-3

GARTNER, L. P.; HIATT, J. L. Tratado de histologia. Rio de Janeiro: Guanabara Koogan, 1999. 250 p.

GEORGE, L. L.; ALVES, C. E. R.; CASTRO, R. R. L. Q. Histologia comparada. 2. ed. São Paulo: Roca, 1998.

HODGES, R. D. The histology of the fowl. London: Academic Press, inc, 1974. p. 64-90.

HUCHZERMEYER, F. W. Doenças dos avestruzes e outras ratitas. Jabuticabal: Funep, 2000. p. 17-27.

ILLANES, J. Descripción histológica de los diferentes segmentos del aparato digestivo de avestruz (Struthio camelus var. domesticus). International Journal of Morphology, v. 24, n. 2, p. 205-214, 2006.

JUNQUEIRA, L. C.; CARNEIRO, J. Histologia básica. 9. ed. Rio de Janeiro: Guanabara Koogan, 2004. p. 220-267.

MCLELLAND, J. Sistema digestivo das aves. In: GETTY. R. Sisson/Grossman anatomia dos animais domésticos. 5. ed. Rio de Janeiro: Guanabara Koogan, 1986. p. 1754-1763.

MONTEIRO, C. M. R.; SOUZA, N. T. M.; CARVALHO, R. G.; SOUZA, W. M. Análise histológica do trato gastrintestinal de avestruzes jovens (Struthio camelus Linnaeus, 1758). Biotemas, v. 22, n. 3, p. 149-155, 2009.

SAMUELSON, D. A. Texbook of veterinary histology. Missouri: Elsevier, 2007. 546 p.

YOUNG, B.; HEATH, J. W. Histologia funcional: texto e atlas em cores. 4. ed. Rio de Janeiro: Guanabara Koogan, 2001. 415 p. 